\title{
Serological report of pandemic (H1N1) 2009 infection among cats in Northeastern China in 2012-02 and 2013-03
}

Fu-Rong Zhao ${ }^{1 \dagger}$, Chun-Guo Liu ${ }^{1,2,3 \dagger}$, Xin Yin ${ }^{1,2,3}$, Dong-Hui Zhou' ${ }^{1}$ Ping Wei ${ }^{1,3^{*}}$ and Hui-Yun Chang ${ }^{1 *}$

\begin{abstract}
Background: Influenza A virus has a wide range of hosts. It has not only infected human, but also been reported interspecies transmission from humans to other animals, such as pigs, poultry, dogs and cats. However, prevalence of A (H1N1) pdm09 influenza virus infections in cats in northeastern China is unknown. Therefore, the prevalence of A (H1N1) pdm09 influenza virus infections was performed among cats in northeastern China in this study.

Findings: Of all samples in this study, the overall seroprevalence of pandemic (H1N1) 2009 infection in cats was 21\% (240/1140). It also showed a higher prevalence rate of pandemic(H1N1) 2009 infection in pet cats (30.6\%) than roaming cats (11\%) based on NT. In addition, the results also showed a trend of difference in term of species of cats and it was statistically significant.

Conclusions: This is the first survey on the seroprevalence of pandemic (H1N1) 2009 infection among cats in northeastern China. This study has observed a relatively high seroprevalence of pandemic (H1N1) 2009 among different cat populations in northeastern China, similar seroprevalence studies should be conducted elsewhere.
\end{abstract}

Keywords: Pandemic (H1N1) 2009, Cats, Serological

Influenza A virus has a wide range of hosts. Often the susceptibility of the species is dependent upon the characteristics of the virus and host. Numerous subtypes of influenza A viruses, including influenza A pandemic H1N1 2009 virus, have been shown to cross-species transmission. Since 2009, a novel influenza A virus (H1N1), now called A (H1N1) pdm09 influenza virus, has caused human influenza outbreaks in North America [1] and a worldwide pandemic [2-4]. To date, it has not only infected human, but also been reported interspecies transmission from humans to other animals, such as pigs, poultry, dogs [5-7].

Recently, the reports have shown that cats can also infected A (H1N1) pdm09 influenza virus [5,8]. Due to frequent cohabitation and close contacts with humans and other animals, cats are uniquely positioned to serve

\footnotetext{
*Correspondence: weiiping@126.com; changhuiyun@126.com

${ }^{\dagger}$ Equal contributors

'State Key Laboratory of Veterinary Etiological Biology, Lanzhou Veterinary Research Institute, Chinese Academy of Agricultural Sciences, Lanzhou, Gansu Province 730046, People's Republic of China

${ }^{3}$ Northeast Agricultural University, College of Veterinary Medicine, Harbin, Heilongjiang Province 150030, People's Republic of China

Full list of author information is available at the end of the article
}

as reservoirs for influenza virus infection both within a household and within the larger farm or rural environment in China $[9,10]$. However, prevalence of A (H1N1) pdm09 influenza virus infection in cats in northeastern China is unknown. Therefore, the prevalence of A (H1N1) pdm09 influenza virus infections was performed among cats in northeastern China in this study.

A total of 1140 feline blood samples were collected from 56 different pet hospitals and four small animal shelters around northeastern China, from February 2012 to March 2013. The geographical and prevalent distribution of the samples has been concerned. Haerbin, Changchun and Shenyang were selected since they are the most densely populated area of commerce in northeastern China. Dalian was also included as it is the trade zone with large-scale breeding of poultry and pigs in northeastern China. The geographical location of serum samples of collection in northeastern China was displayed, please see the Figure 1. 660 blood samples from pet cats in hospitals and 480 blood samples from roaming cats were obtained. In each city, we selected the single largest small shelter. These serum samples were separated by centrifugation at 3,000 rpm 


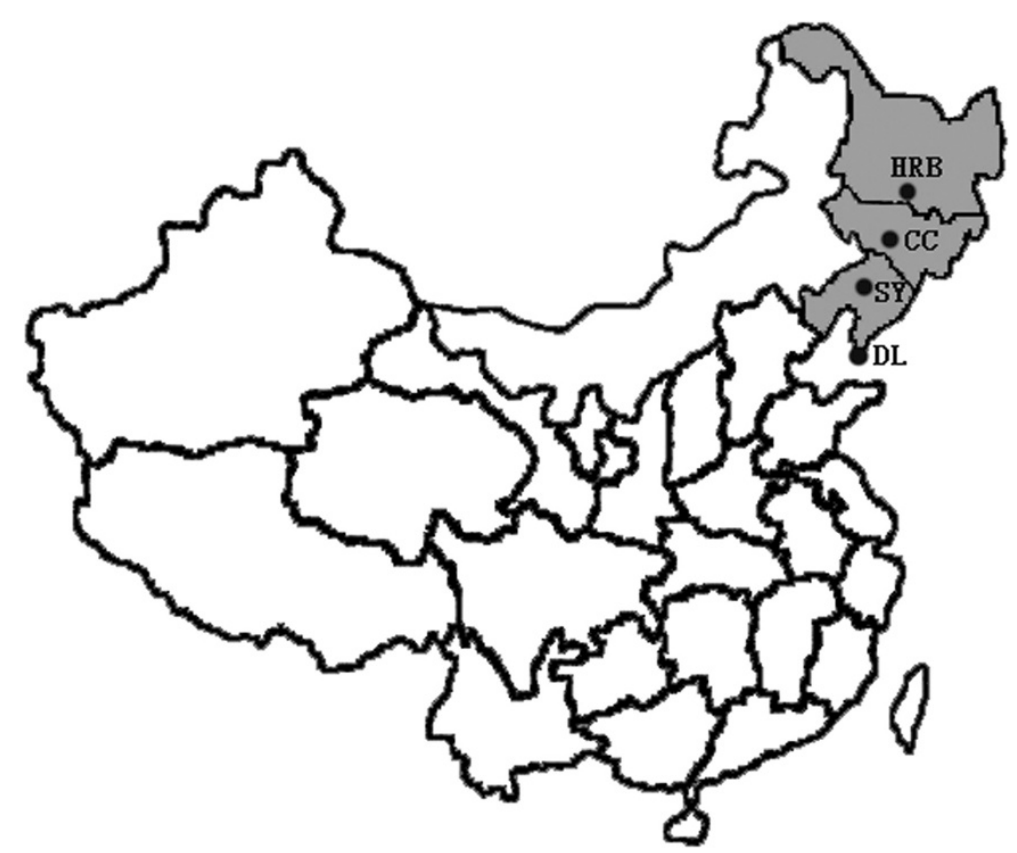

Figure 1 Survey sites in northeastern China where the sero-study was conducted. HRB: Haerbin; CC: Changchun; SY: Shengyang; DN: Dalian.

for $15 \mathrm{~min}$, and supernatants were transferred to a new eppendorf tubes and stored at $-20^{\circ} \mathrm{C}$ until tested for antibodies against influenza A virus [11]. Additionally, in order to have a timely data for pandemic (H1N1) 2009 prevalence in northeastern China, 115 blood samples were retrospectively analyzed from pet dogs and pet cats in Harbin in 2008. All samples were tested by hemagglutination inhibition (HI) and Neutralization (NT) assay, according to the recommended procedures as previously reported $[10,12]$. HI titer $\geq 40$ and NT titer $\geq 40$ are considered as positive and indicate previous infection [12]. Influenza virus used in this study was A/California/7/2009(H1N1pdm09) [pandemic (H1N1) 2009 virus]. We additionally studied the sera for HI antibodies against three other viruses: a human seasonal H1N1 influenza virus A/Brisbane/59/2007(H1N1) and A/ canine/Guangdong/2/2011(H3N2), a recently circulating
H3N2 canine influenza virus (CIV) in dogs in China. The comparison of categorical variables between cat samples was performed with chi-square test where appropriate. Statistical significance was defined as $p<0.05$. The data was analyzed with SAS software, version 9.1 [11].

A total of 1255 serum samples were examined by NT and HI for pandemic (H1N1) 2009 antibodies. The serological screening revealed 21\% pandemic (H1N1) 2009 infection in cats in northeastern China based on NT. It also showed a higher prevalence rate of pandemic (H1N1) 2009 infection in pet cats $(30.6 \%)$ than roaming cats $(11 \%)$ based on NT $(\mathrm{p}=0.0032$, Table 1$)$. The results from $\mathrm{HI}$ also showed a trend of difference in term of species of cats and it was statistically significant $(\mathrm{P}=0.002)$. The prevalence of the infection also showed a geographical difference in roaming cats as prevalent in Harbin and Changchun (20.8\% and 23.3\%) and absent in Shenyang and Dalian (Table 1). In addition,

Table 1 Seroprevalence of pandemic (H1N1) 2009 in cats in different cities in northeastern China

\begin{tabular}{|c|c|c|c|c|c|c|c|c|}
\hline \multirow[t]{3}{*}{ City } & \multicolumn{3}{|l|}{ Roaming cats } & \multirow{3}{*}{ OR $(95 \% C I)^{a}$} & \multicolumn{3}{|l|}{ Pet cats } & \multirow{3}{*}{ OR $(95 \% \mathrm{Cl})^{\mathrm{a}}$} \\
\hline & \multirow[t]{2}{*}{ No. examined } & \multicolumn{2}{|c|}{ Seroprevalence (\%) } & & \multirow[t]{2}{*}{ No. examined } & \multicolumn{2}{|c|}{ Seroprevalence (\%) } & \\
\hline & & NT & $\mathrm{HI}$ & & & NT & $\mathrm{HI}$ & \\
\hline Haerbin & 120 & $20.8 \%(25 / 120)$ & $21.7 \%(26 / 120)$ & Reference & 165 & $36.4 \%(60 / 165)$ & $34.5 \%(57 / 165)$ & Reference \\
\hline Changchun & 120 & $23.3 \%(28 / 120)$ & $20.8 \%(25 / 120)$ & $1.05[0.57-1.95]$ & 165 & $32.7 \%(54 / 165)$ & $28.5 \%(47 / 165)$ & $1.37[0.86-2.18]$ \\
\hline Shenyang & 120 & $0(0 / 120)$ & $0(0 / 120)$ & $67.58[4.06-1124]$ & 165 & 27.9\%(49/165) & $30.3 \%(50 / 165)$ & $1.21[0.76-1.93]$ \\
\hline Dalian & 120 & $0(0 / 120)$ & $0(0 / 120)$ & $67.58[4.06-1124]$ & 165 & $23.6 \%(39 / 165)$ & $21.2 \%(35 / 165)$ & $1.96[1.20-3.20]$ \\
\hline Total & 480 & $11 \%(53 / 480)$ & $10.7 \%(51 / 480)$ & & 660 & $30.6 \%(202 / 660)$ & $28.0 \%(189 / 660)$ & \\
\hline $\mathrm{OR}(95 \% \mathrm{Cl})^{\mathrm{b}}$ & & Reference & Reference & & & $0.28[0.20-0.39]$ & $0.30[0.21-0.41]$ & \\
\hline
\end{tabular}

${ }^{\mathrm{a}}$ The statistical tests about the association between different cities in $\mathrm{HI}$ tests.

${ }^{\mathrm{b}}$ The statistical tests about the association between roaming and pet cats; $\mathrm{OR}$, odds ratio; $\mathrm{Cl}$, confidence intervals. 
Table 2 Seroprevalence of pandemic (H1N1) 2009 in cats of different ages and genders, in northeastern China using the NT and $\mathrm{HI}$ assay

\begin{tabular}{llll}
\hline Variable & Class & Positive rate & \\
\cline { 3 - 4 } & & NT & HI \\
\hline Gender & Male & $28.3 \%(163 / 576)$ & $26.5 \%(153 / 576)$ \\
& Female & $17.6 \%(99 / 564)$ & $16.3 \%(92 / 564)$ \\
\hline Variable $^{\mathbf{A}}$ & $\mathbf{n}$ & $\begin{array}{l}\text { Unadjusted OR } \\
(\mathbf{9 5 \%} \mathbf{C l})\end{array}$ & $\begin{array}{l}\text { Adjusted OR } \\
(\mathbf{9 5 \%} \mathbf{C l})\end{array}$ \\
\hline
\end{tabular}

Raising pattern

Age

$\begin{array}{lccc}\text { Less than } 4 \text { years } & 770 & 1.5[0.71-1.93] & 0.97[0.66-1.39] \\ \begin{array}{l}4 \text { years and more } \\ \text { Gender }\end{array} & 250 & \text { Reference } & - \\ \quad \text { Male } & 516 & 1.72[1.12-1.99] & 1.44[0.91-1.70] \\ \quad \text { Female } & 504 & \text { Reference } & -\end{array}$

AUnadjusted and adjust with logistic regression odds ratios for elevated $\mathrm{HI}$ and NT antibodies against pandemic ( $\mathrm{H} 1 \mathrm{~N} 1$ ) influenza A virus among different cat populations in northeastern China.

the factors of the gender and age of the cats were also analyzed as contributors to pandemic (H1N1) 2009 prevalence. In the Table 2, while no influence of age (seropositive data not shown) was found on cats infection with pandemic (H1N1) 2009, genders associated with the pandemic (H1N1) 2009 seropositivity by both HI and NT assay was significantly $(\mathrm{p}<0.05)$. In addition, a total of 115 serum samples collected in 2008 had no HI or NT antibodies against A/California/7/2009 (data not shown). To rule out non-specific cross-reactivity, 1140 serum samples were titrated against seasonal influenza viruses (H1N1). Only twenty-four samples had a HI titer of 1:40 against H1N1 (Table 3). Only ten of these forty seasonal influenza positive-samples were also $\mathrm{HI}$ and NT positive for A/California/7/2009(H1N1pdm09). A total of 111 (9.7\%) sera were positive by $\mathrm{HI}$ assay against H3N2 CIV (Table 3).

Few seroprevalence studies on pandemic (H1N1) 2009 infections have been attempted in cats worldwide. The prevalence of this virus infection in cats in mainland China remains unknown. This is the first survey on the seroprevalence of pandemic (H1N1) 2009 infection in cats in northeastern China. Of all sera from cats in this study, 21\% was identified as pandemic (H1N1) 2009 positive. In another conducting the seroprevalence of antibodies against (H1N1) pdm09 among cats in small cities of southern China was only $1.2 \%$ in 2011 [11]. Our increased antibody prevalence might be explained a number of ways. Perhaps cats were at a higher probability of infection in northeastern China, due to they exposures in dense populations of humans with high influenza A (H1N1) pdm09 attack rates. The difference might also be explained by the one year temporal difference between cats sampled in southern China in that the northeastern China cats had 1 more years to acquire influenza A (H1N1) pdm09 virus infection. Additionally, the prevalence of seropositive pandemic (H1N1) 2009 in male cats versus female cats suggests that the male cats may be more susceptible $(\mathrm{P}<0.05)$ to the pandemic $(\mathrm{H} 1 \mathrm{~N} 1) 2009$ infections (Table 2). We hypothesize that relatively high A (H1N1) pdm09 transmission may have occurred between humans and cats during the period of virus infection in the human population. This hypothesis is supported by our observation that pet cats were more likely to have evidence of previous infection with A (H1N1) pdm09 that were roaming cats $(30.6 \%$ vs $11 \%, \mathrm{P}$ $=0.0032)$ and also suggests a likely transmission between infected owners and their pets by close contact. Serological evidence of A (H1N1) pdm09 in domestic cats has been reported in the past. In a sero-survey conducted in Italy in 2009, a contrary low prevalence had been observed among dogs, while no cats were reported to have antibodies against $\mathrm{A}(\mathrm{H} 1 \mathrm{~N} 1)$ pdm09 in the screen [8]. A similar high prevalence of $21.8 \%$ and $22.5 \%$ were recorded in a population of cats in the United States, but the study sample comprised animals with a history of respiratory disease [10]. We hypothesized the sustained transmission of the influenza A (H1N1) pdm09 virus in the human population in our study area. In addition, it should be noted that 240 samples from the two small animal shelters in Harbin and Changchun had exposure to pandemic (H1N1) 2009 before sample collection. The higher prevalence of seropositive pandemic A (H1N1) pmd09 among Harbin and Changchun cats versus Shenyang and Dalian is unexplained.

Since cats may be exposed to different influenza virus subtypes, including human-avian and avian-origin influenza viruses, their potential role in the epidemiology of influenza

Table 3 Prevalence of elevated antibody titers against a canine influenza H3N2, a seasonal influenza H1N1, and A (H1N1)pdm09 among cats by hemagglutination inhibition (HI) assay, northeastern China ${ }^{a}$

\begin{tabular}{|c|c|c|c|c|c|c|c|c|}
\hline \multirow[t]{2}{*}{$\mathrm{HI}$ assay virus } & \multirow[t]{2}{*}{ Number } & \multicolumn{5}{|c|}{ Antibody titer } & \multirow{2}{*}{$\begin{array}{l}\text { Number of specimens } \\
\text { with titers } \geq 1: 40(\%)\end{array}$} & \multirow[b]{2}{*}{$\mathrm{OR}(95 \% \mathrm{Cl})^{\mathrm{b}}$} \\
\hline & & $<1: 20$ & $1: 20$ & $1: 40$ & $1: 80$ & $\geq 1: 160$ & & \\
\hline $\mathrm{H} 3 \mathrm{~N} 2$ & 1140 & 704 & 325 & 51 & 24 & 36 & $111(9.7)$ & Reference \\
\hline $\mathrm{H} 1 \mathrm{~N} 1$ & 1140 & 911 & 205 & 16 & 5 & 3 & $24(2.1)$ & $5.02[3.20-7.86$ \\
\hline Pdm09 & 1140 & 518 & 382 & 123 & 52 & 65 & $240(21.5)$ & $0.40[0.32-0.52$ \\
\hline
\end{tabular}

${ }^{\mathrm{a}} \mathrm{H} 1 \mathrm{N1}$ = A/Brisbane/59/2007(H1N1); H3N2 = A/canine/Guangdong/2/2011(H3N2); Pdm09 = A/California/7/2009(H1 N1 pdm09).

${ }^{\mathrm{b}}$ The statistical tests about the association between difference virus strains; OR, odds ratio; $\mathrm{Cl}$, confidence intervals. 
virus should be further investigated. In summary, this study has observed a relatively high seroprevalence of pandemic (H1N1) 2009 in cats in northeastern China, similar seroprevalence studies should be conducted elsewhere. The studies showed that the prevalence for A (H1N1) pdm09 in human was correlated with age and population density. Preexisting antibody may have protected the very old from A (H1N1) pdm09 infection, while original antigenic sin and immunosenescence may have contributed to greater severity once infected [13-15]. Compare with all serum samples collected in 2008 had no HI and NT antibodies against A/California/7/2009, these results reflect the pandemic (H1N1) 2009 had been spread in cats. Concerns of rapid spread in small animal shelters and household may be needed. These observations highlight the need for monitoring cats in pet hospitals and small animal shelters are necessary for us to understand what roles cats plan in the ecology of influenza A virus.

\section{Competing interests}

The authors declare that they have no competing interests.

\section{Authors' contributions}

FRZ and HYC designed the experiments. XY, DHZ carried out the test. PW CGL and FRZ drafted the manuscript. All authors have read and approved the final manuscript.

\section{Acknowledgements}

This work was supported by National Transgenic Project of China (2011ZX08011-004), and Basic Conditions for Science and Technology Projects of Lanzhou City (2012-2-71).

\section{Author details}

${ }^{1}$ State Key Laboratory of Veterinary Etiological Biology, Lanzhou Veterinary Research Institute, Chinese Academy of Agricultural Sciences, Lanzhou, Gansu Province 730046, People's Republic of China. ${ }^{2}$ State Key Lab of Veterinary Biotechnology, Harbin Veterinary Research Institute of Chinese Academy of Agricultural Sciences, Harbin, Heilongjiang Province 150001, People's Republic of China. ${ }^{3}$ Northeast Agricultural University, College of Veterinary Medicine, Harbin, Heilongjiang Province 150030, People's Republic of China.

\section{Received: 25 November 2013 Accepted: 4 March 2014}

Published: 14 March 2014

\section{References}

1. Centers for Disease C, Prevention: Swine influenza A (H1N1) infection in two children-Southern California, March-April 2009. MMWR Morb Mortal Wkly Rep 2009, 58:400-402.

2. Kilbourne ED: Influenza pandemics of the 20th century. Emerg Infect Dis 2006, 12:9-14

3. Organization WH: Influenza A (H1N1)—update 48. In 2009. Available from http://www.who.int/csr/don/2009_06_12/en/.

4. Organization WH: World now at the start of 2009 influenza pandemic. In 2009. Available from http://www.who.int/mediacentre/news/statements/ 2009/h1n1_pandemic_phase6_20090611/en/.

5. Sponseller BA, Strait E, Jergens A, Trujillo J, Harmon K, Koster L, Jenkins-Moore M, Killian M, Swenson S, Bender H, Waller K, Miles K, Pearce T, Yoon KJ, Nara P: Influenza A pandemic (H1N1) 2009 virus infection in domestic cat. Emerg Infect Dis 2010, 16:534-537.

6. Su S, Li HT, Zhao FR, Chen JD, Xie JX, Chen ZM, Huang Z, Hu YM, Zhang MZ, Tan LK, Zhang GH, Li SJ: Avian-origin H3N2 canine influenza virus circulating in farmed dogs in Guangdong, China. Infect Genet Evol 2013, 14:444-449.

7. Association AVM: N.Y. dog infected with $\mathrm{H} 1 \mathrm{~N} 1$; study shows virus non pork. In 2010. Available from https://www.avma.org/News/JAVMANews/ Pages/100201e.aspx.
8. Dundon WG, De Benedictis P, Viale E, Capua I: Serologic evidence of pandemic (H1N1) 2009 infection in dogs, Italy. Emerg Infect Dis 2010, 16:2019-2021.

9. Su S, Qi W, Chen J, Zhu W, Huang Z, Xie J, Zhang G: Seroepidemiological evidence of avian influenza A virus transmission to pigs in southern China. J Clin Microbiol 2013, 51:601-602.

10. Ali A, Daniels JB, Zhang Y, Rodriguez-Palacios A, Hayes-Ozello K, Mathes L, Lee CW: Pandemic and seasonal human influenza virus infections in domestic cats: prevalence, association with respiratory disease, and seasonality patterns. J Clin Microbiol 2011, 49:4101-4105.

11. Su S, Yuan L, Li H, Chen J, Xie J, Huang Z, Jia K, Li S: Serologic evidence of pandemic influenza virus H1N1 2009 infection in cats in China. Clin Vaccine Immunol 2013, 20:115-117.

12. An DJ, Jeoung HY, Jeong W, Chae S, Song DS, Oh JS, Park BK: A serological survey of canine respiratory coronavirus and canine influenza virus in Korean dogs. J Vet Med Sci 2010, 72:1217-1219.

13. Xu C, Bai T, Iuliano AD, Wang M, Yang L, Wen L, Zeng Y, Li X, Chen T, Wang W, Hu Y, Yang L, Li Z, Zou S, Li D, Wang S, Feng Z, Zhang Y, Yu H, Yang W, Wang $Y$, Widdowson MA, Shu Y: The seroprevalence of pandemic influenza H1N1 (2009) virus in China. PLoS One 2011, 6(4):e17919.

14. Zhang X, He J, Li L, Zhu X, Ke C, Ni H, Hou N, Zhong H, Wu J: Serologic survey of the pandemic H1N1 2009 virus in Guangdong Province, China: a cross sectional study. PLoS One 2011, 6(8):e23034.

15. Liu T, Li Z, Song S, Zhang S, Wang Y, Wang L, Xu A, Wang X, Bi Z: Seroepidemiological study of influenza A (H1N1) pdm09 virus following the 2009-2010 wave in Shandong Province, China. Scand J Infect Dis 2013, 45(7):552-556.

doi:10.1186/1743-422X-11-49

Cite this article as: Zhao et al:: Serological report of pandemic (H1N1) 2009 infection among cats in Northeastern China in 2012-02 and 2013-03. Virology Journal 2014 11:49.

\section{Submit your next manuscript to BioMed Central and take full advantage of:}

- Convenient online submission

- Thorough peer review

- No space constraints or color figure charges

- Immediate publication on acceptance

- Inclusion in PubMed, CAS, Scopus and Google Scholar

- Research which is freely available for redistribution 